\title{
Structural Equation Model Relationship Between Policy, Work Breakdown Structure (WBS), Guidelines, Information System (IS), and Building Information Modeling (BIM) on Maintenance Perfomance of High Rise Building
}

\author{
Leni Sagita Riantini', Nurul Inayah Wardahni' ${ }^{2}$, Yusuf Latief ${ }^{3}$, and Rossy Armyn Machfudiyanto ${ }^{4}$ \\ ${ }^{1}$ Ph.D., Department of Civil Engineering, Faculty of Engineering, Universitas Indonesia, Indonesia. \\ ${ }^{2}$ Student, Department of Civil Engineering, Faculty of Engineering, Universitas Indonesia, Indonesia. \\ ${ }^{3}$ Professor, Department of Civil Engineering, Faculty of Engineering, Universitas Indonesia, Indonesia. \\ ${ }^{4}$ Doctor, Department of Civil Engineering, Faculty of Engineering, Universitas Indonesia, Indonesia.
}

\begin{abstract}
A high-rise building is a building with a minimum height of 22 meters or equivalent to 8 stories that functions as a residence, a commercial area, or an office that are capable of reducing horizontal land use. In the duration of its operational use, there are many building administrators that have not conducted effective and efficient building maintenance, resulting in subpar achievement of maintenance performance indicators. Utilizing ICT (Information and Communication Technology) in a high-rise building's maintenance systems allows for this process to be more effective and efficient. Therefore, the components of e-maintenance for high-rise buildings must be identified. This research aims to analyse the relationship that policies, WBS, guidelines, information system, and BIM has towards the performance of maintenance in high-rise buildings by identifying indicators from each variables that affects the performance of maintenance of high-rise buildings, with the analysis conducted using the SEM-PLS analysis method. The results from this analysis produces an $r$-square value of 0.794 for maintenance performance, as well as showing 8 significant connections between the variables of e-maintenance of highrise buildings.
\end{abstract}

Keywords: E-Maintenance, WBS, Information System, BIM, Maintenance Performance, High Rise Building

\section{INTRODUCTION}

High-rise buildings are a solution for the increasing demand for land use with limited availability of land in urban areas [1]. The function of said high-rise buildings differ from one to another, with some serving as residential buildings and some others as office buildings, hotels, etc.[2]. Generally speaking, all buildings have the same life cycle: planning stage, design stage, construction stage, operational stage, and maintenance stage. During the whole duration of the life cycle, the performance of the structure as well as its facilities will change and degrade as the building's structural elements experience aging and deformation [3]. Therefore, maintenance and inspections needs to be conducted during the whole period where the building is used, with aims to provide safety to the users and the owners of the building [4]. In Indonesia, the maintenance of a building is commonly done in a conventional way. However, according to [5], Maintenance Management System (MMS) needs to be developed with the most recent technology, since conventional methods tend to be both cumbersome and ineffective. As an effect of globalization and the rapid development of ICT, a building's maintenance is now capable of being integrated with ICT, often referred to as e-maintenance [6]. The implementation of ICT in a maintenance system can provide powerful strategic and tactical tools for organizations in managing facilities [7]. This research is a continuation of an earlier research regarding the elements and indicators of emaintenance of high-rise buildings. From that research, the components of e-maintenance are identified, namely policy, work breakdown structure (WBS), guidelines, information system (IS), and building information modelling (BIM). This research then aims to analyse the relationships between these variables of e-maintenance of high-rise buildings that have been identified, so that this research can be used as a basis for a high-rise building maintenance management strategy.

\section{LITERATURE REVIEW}

\section{II.I Maintenance Policy}

Policy is a critical concept in the management of the heterogenic distribution of system, network, and implementation [8]. According to [9], there are 5 (five) types of maintenance policies: Corrective Maintenance, Preventive Maintenance, Predictive Maintenance, Autonomous Maintenance, and Design Out Maintenance. All these maintenance policies must be optimal where the implementation of these policies are capable in reducing maintenance costs, maximizing system reliability, reducing costs of maintenance system when the desired reliable system indicators are achieved, and maximizing the measurement of system reliability when the desired reliable system indicators are achieved. 


\section{II.II WBS}

WBS (Work Breakdown Structure) is a hierarchical structure that defines and establishes the entirety of a project in a deliverable-oriented manner where the levels in the hierarchy shows the detailed definitions of a construction project [10]. According to [11], WBS is a project management tool to decompose projects into smaller components (tree structure) through a framework that allows better control over project costs, schedule, and scope.

\section{II.III Building Maintenance Guidelines}

According to the Regulation of the Minister of Public Works Number 24, 2008 regarding the Guidelines for Building Maintenance, the maintenance of building covers requirements related with building safety, health, comfort, and ease. The procedures and methods for building maintenance as stated in the Regulation of the Minister of Public Works Number 24, 2008 are building maintenance procedures and methods, building maintenance working program, tools and equipment for building maintenance works, as well as building maintenance performance standards.

\section{II.IV Information System}

Information system is a series of interconnected components that collect, process, store, and distribute information to support decision making and control in an organization. An information system consists of critical information regarding parties, locations, and other things in an organization and its surroundings [12]. By integrating an information system, a business can be successful in competing with other companies, elevate economic indicators, increase productivity and efficiency, reduce costs, and several other advantages [13]. According to [14], the role of information system in a maintenance system is in the data collection of relevant events during the operation and maintenance of technical systems, the processing of data to produce information diagnosis, forecasting, planning, decision making, and the realization and control of corrective and preventive maintenance.

\section{II.V BIM}

According to [3] , BIM is a technology that produces and manages all information from different aspects of a project, from its concept design through to its maintenance stage. BIM is capable in providing a $3 \mathrm{D}$ digital visualization. Moreover, BIM is capable in storing not only geometric data, but also all necessary semantic data such as element function, material properties, construction details, schedule, etc. [15]. According to [16], the adoption of BIM allows for real-time coverage on the status of the facilities. Location identification and navigation can also be realized through BIM, which allows for the reducing of time required and preventing unexpected losses. According to [17], the implementation of BIM in acquiring design information, construction information, and building operational information and integrating it with one another can help elevate the building's maintenance system.

\section{II.VI Building Maintenance Performance}

According to [18], the measure of performance is a fundamental and critical aspect in the principle of management, allowing for the identification of the disparity between target performance and actual performance. The performance of maintenance is the state or condition of an action or process of maintenance, measured from time to time [19]. The management of the physical performance of assets is in line with the success of business process, one of which is the rehabilitation of said asset's physical conditions.

\section{II.VII Inter-Variable Relationships of E-Maintenance of High-Rise Buildings}

\section{II.VII.I Relationship between Policy and WBS}

According to [10] [20], the formulation of WBS requires five inputs: scope management plan, project scope statement, document requirements, company environmental factors, and organization process assets. The fifth input, organization process assets, consists of the planning, process, policies, procedures, and specific knowledge basis that are utilized by the organization to conduct or manage projects. In this case, policies, procedures, and other aspects mentioned above are a template for the formulation of WBS.

\section{II.VII.II Relationship between Policy and Guidelines}

According to [21], policies and procedures manual (PPM) provides a guideline that is required to fulfil the requirements and objectives of an organization. Policies for maintenance provides guidelines for the implementation of maintenance strategies that are selected and are effective [22].

\section{II.VII.III Relationship between Policy, Guidelines, and IS}

According to O'Brien and Marakas in [23], information system is a combination of human, software, hardware, communication network, source of data, policies and guidelines that store, collect, process, and distribute information in an organization. The lack of policy, standards, and guidelines in the development of a system might cause the documentation system to fail in fulfilling the information necessities in an information system [24].

\section{II.VII.IV Relationship between Policy and BIM}

According to [25], BIM combines the procedures of software processing and information to design, document, visualize, and report information related to the building and its facilities which have been integrated with policies, standards, regulations, guidelines, etc. Based on this, the industry must then develop an acceptable process and policy that supports the use of BIM [26]. 


\section{II.VII.V Relationship between Policy and Maintenance Performance}

According to [27], in order to increase maintenance performance, it is necessary for the development of maintenance programs based on maintenance objectives, policies, organization, resources, and capabilities to be done.

\section{II.VII.VI Relationship between WBS and Guidelines}

According to [28] [29], the development of guidelines on building maintenance is made based on WBS. This is because the WBS is able to provide information on the materials and specifications of certain aspects of a building.

\section{II.VII.VII Relationship between WBS and IS}

According to [30], the method commonly used for building maintenance is by integrating an information technology (IT) system, or more specifically the software development life cycle (SDLC) method. This method consists of 7 (seven) stages: the definition stage, the specification (requirements) stage, the construction stage, the testing stage, the installation stage, the operation stage, and the maintenance stage. Each of the stages covers a complete statement of scope, a detailed project plan, resource estimate, duration and costs estimate, and several other items that are obtainable through a work breakdown structure [31].

\section{II.VII.VIII Relationship between WBS and BIM}

According to [32] [33], the WBS is used as a source of information needed in the database for the modelling of the structure in 3D or in BIM. In this case, the WBS and the WBS codes have an automated connection system for the tasks and activities of the project with the BIM objects being created from the multi-dimensional BIM database.

\section{II.VII.IX Relationship between WBS and Maintenance Performance}

According to [28] [29], in the process of increasing the maintenance performance of a building, the execution the maintenance needs to be based on its WBS. This is because the WBS facilitates the users in determining the different work and materials needed for each component so that the usage of materials can be made more effective.

\section{II.VII.X Relationship between Guidelines and BIM}

According to [34], the implementation of BIM in a project requires a guideline on good practices for the stakeholders of the project so that the BIM can be more reliable and so the connectivity of information in the project can run more efficiently. Thus, there needs to be a standardization of BIM process and a guideline definition on the BIM implementation [35].

\section{II.VII.XI Relationship between Guidelines and Maintenance Performance}

According to [36], a guideline defines the person in charge as well as the procedure for the collection of data and the calculation of indicators needed for the assessment and evaluation of conducted maintenance performances.

\section{II.VII.XII Relationship between IS and BIM}

Information system and building information modelling is (BIM) is closely related to one another. In three-dimensionally modelling the information of a building as means to distribute information and easing project execution, there needs to be an information system that collects data inputs into a certain database that can be processed into the BIM model [32].

\section{II.VII.XII Relationship between IS and Maintenance Performance}

According to [14], the functions of an information system in the management of maintenance are to collect relevant data during the operational period of technical systems and during maintenance, to process data to obtain information diagnosis, to create an estimate of possible events, to conduct planning, to make a decision, and to realize and manage preventive and corrective maintenance.

\section{II.VII.XII Hubungan BIM dan Kinerja Pemeliharaan}

According to [37], in increasing maintenance performance, the building information modelling (BIM) approach is implemented and developed through 3D modelling with aims to manage and maintain facilities, where the model is integrated with information related to previous facility maintenance works and their workers. The maintenance management can then run effectively by achieving the reduction of maintenance costs through energy and resource savings, as well as increasing asset value.

Based on the literature review that has been conducted, the inter-variable relationships in e-maintenance of high-rise buildings can be identified. The relationship model is illustrated in the figure below. 


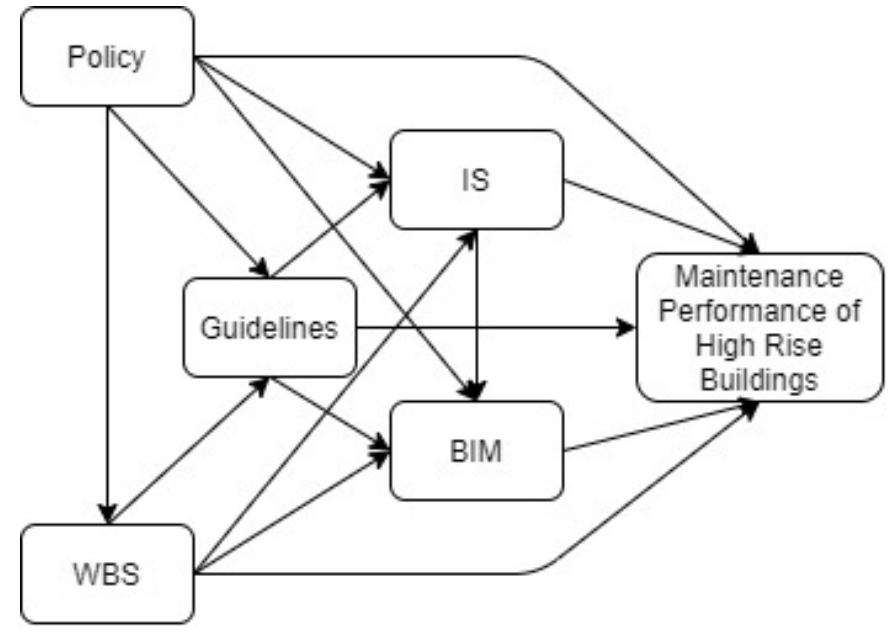

Fig. 1. Conceptual Model of the Inter-Variable Relationships of E-Maintenance of High-Rise Buildings

Fig. 1. illustrates the relationships between the variables, determined by the direction of the arrows, based on the conducted literature review. For example, policy significantly affects WBS, policy significantly affects information system, etc. Following this, the inter-variable relationships will be analysed using the SEM-PLS method.

\section{METHOD}

This research continues upon an earlier research which identifies the elements and indicators of e-maintenance of highrise buildings. In this research, the relationships between the variables will be further analysed based on the results of literature review. A SEM-PLS analysis will be conducted using the elements and indicators of each of the variable that have been obtained in the previous research. Structural Equation Modelling (SEM) is an second generation multivariate data analysis method that is often used in research due to its ability to assess linear and additive causal models and is supported by theory [38]. This approach is done based on variance with the method used being the least square method.

According to [39], in the SEM-PLS approach, a structural model and its measurements is used as a basis for an inner model and an outer model. To develop path models, the structural theory and the measurement theory that specifies relationships between elements of the path model using bootstrapping must be initially illustrated. In this research, the structural theory illustration is Fig.1. which is the synthesis of a research on the inter-variable relationships that have been constructed based on literature review. The measurement used in this research is using a likert scale of 1-5 where 1 represents 'strongly disagree' and 5 represents 'strongly agree' in relation to the significance of the relationships between the variables.

The determining of sample size for the SEM-PLS analysis then refers to [39].
Table 1. Minimum Sample Size Required

\begin{tabular}{|c|c|}
\hline $\begin{array}{c}\text { Minimum } \\
\text { sample size } \\
\text { required }\end{array}$ & $\begin{array}{c}\text { Maximum \# of arrows pointing at a } \\
\text { latent variable in the model }\end{array}$ \\
\hline 52 & 3 \\
\hline 59 & 4 \\
\hline 65 & 5 \\
\hline 70 & 6 \\
\hline 75 & 7 \\
\hline 80 & 8 \\
\hline 84 & 9 \\
\hline 88 & 20 \\
\hline 91 & 2013 \\
\hline
\end{tabular}

Source: Wong, 2013

The maximum number of arrows pointing at a latent variable in the model of this research is 5 arrows, so the minimum sample required in this research is 70 respondents. The results of the SEM-PLS analysis will then be validated by experts on the field of high-rise building maintenance with a minimum experience of 15 years.

\section{RESULT}

Based on the bootstrapping results of the SEM-PLS analysis, an r-square value of 0.794 for maintenance performance is acquired. Furthermore, the result of the relationship model from the SEM-PLS analysis is as shown in the table below.

Table 2. Analysis Results on Inter-Variable Relationships based on Results from SEM-PLS

\begin{tabular}{|l|c|c|}
\hline Hypothesis Test Results & $\begin{array}{c}\text { T } \\
\text { Statistics }\end{array}$ & $\begin{array}{c}\text { Inter-Variable } \\
\text { Relationship }\end{array}$ \\
\hline Policy -> WBS & 9.453 & Significant \\
\hline $\begin{array}{l}\text { Policy -> Information } \\
\text { System }\end{array}$ & 8.095 & Significant \\
\hline $\begin{array}{l}\text { Guidelines -> } \\
\text { Maintenance Performance }\end{array}$ & 7.782 & Significant \\
\hline $\begin{array}{l}\text { Information System -> } \\
\text { BIM }\end{array}$ & 3.774 & Significant \\
\hline WBS -> Guidelines & 3.082 & Significant \\
\hline Guidelines -> BIM & 2.964 & Significant \\
\hline $\begin{array}{l}\text { BIM -> Maintenance } \\
\text { Performance }\end{array}$ & 1.983 & Significant \\
\hline $\begin{array}{l}\text { WBS -> Information } \\
\text { System }\end{array}$ & 1.971 & Significant \\
\hline
\end{tabular}




\begin{tabular}{|l|c|c|}
\hline $\begin{array}{l}\text { Information System -> } \\
\text { Maintenance Performance }\end{array}$ & 1.822 & Insignificant \\
\hline Policy -> BIM & 1.705 & Insignificant \\
\hline $\begin{array}{l}\text { Policy -> Maintenance } \\
\text { Performance }\end{array}$ & 1.314 & Insignificant \\
\hline $\begin{array}{l}\text { WBS -> Maintenance } \\
\text { Performance }\end{array}$ & 1.217 & Insignificant \\
\hline
\end{tabular}

Based on the results from SEM-PLS analysis, from 15 hypotheses, only 8 (eight) hypotheses whose t-statistic values (significance values) are above 1,96 can be accepted. Thus, the relationship model based on SEM-PLS analysis results are as follows.

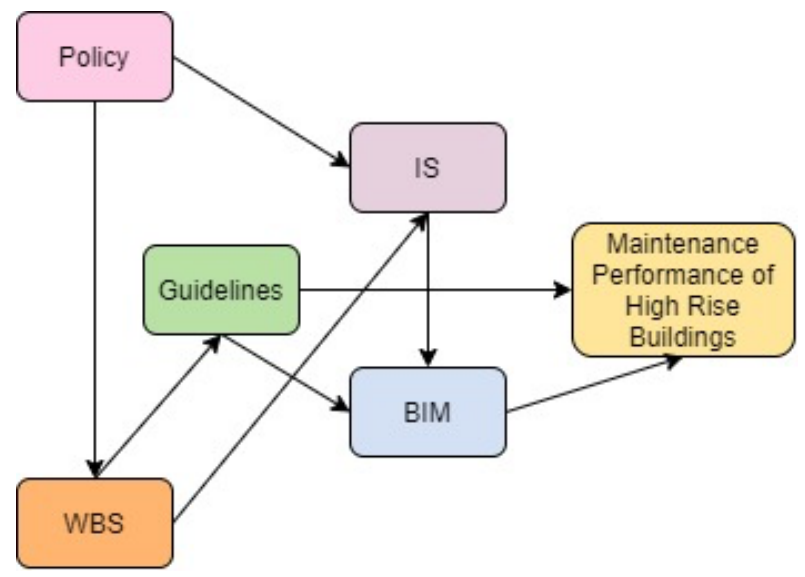

Fig. 2. Inter-Variable Relationship Model for E-Maintenance of High-Rise Buildings based on SEM-PLS

Based on Fig. 2., the inter-variable relationships in emaintenance of high-rise buildings which is the result of bootstrapping on SEM-PLS as precepted by high-rise building maintenance experts are as follows.

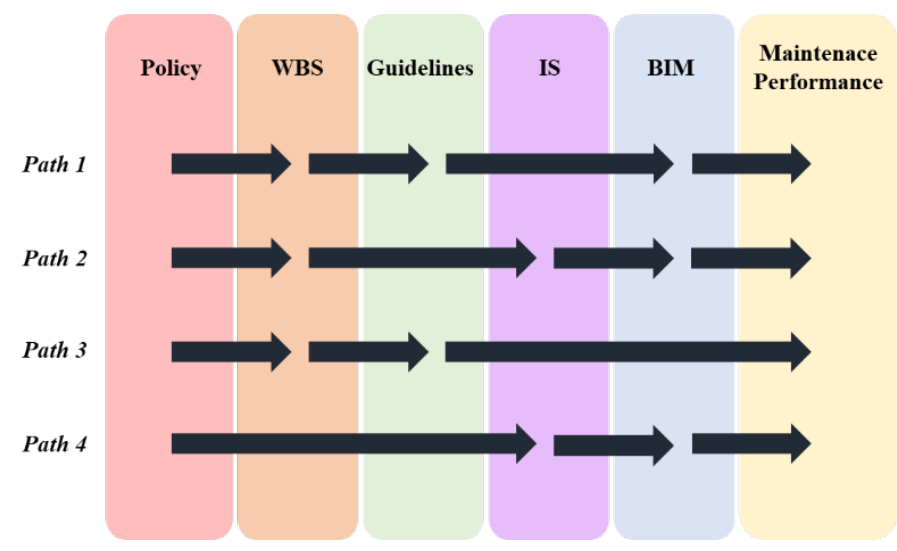

Fig. 3. Significant Inter-Variable Relationship Pattern based on SEM-PLS Analysis Results

Fig. 3. Illustrates the results of the SEM-PLS analysis. As shown in the figure above, there are four relationship paths.
Taking the components of the paths into notice, these four paths can be used as consideration when formulating maintenance strategies in high-rise buildings and as a control scheme in high-rise building maintenance management.

After conducting the SEM-PLS analysis, the results will then be validated by three experts on the field of high-rise building maintenance management. The validation shows that according to the experts, all inter-variable relationship hypotheses are significant, especially the policy to maintenance performance relationship. This statement is in accordance to the literature review.

\section{DISCUSSION}

\section{V.I Gap Analysis}

After the data from SEM-PLS analysis has been processed and validated by experts, it is found that high-rise maintenance practitioners and experts have different perceptions on the matter. This brings about the need for further analysis on the different perceptions which will be done based on literature review. The gap analysis of this research is as follows.

\section{V.I.I Relationship between IS and Maintenance Performance}

The SEM-PLS analysis results show that the relationship between information system and maintenance performance which has a t-statistic value of 1,822 is considered 'insignificant' due to it being lower than 1,96. This result does not go accordingly with expert opinion. According to experts, information system has a significant role in high-rise building maintenance. Information system is highly useful in crosschecking information to the actual conditions of the maintenance works and all its indicators. This opinion is in accordance [14] which states that in maintenance management, information system has a significant role to collect relevant data during the operation of technical system and maintenance, process data and diagnose information, conduct estimates of possible events, act as consideration in decision making, and act as a control mechanism in maintenance.

\section{V.I.II Relationship between Policy and BIM}

The SEM-PLS analysis results show that the relationship between policy and BIM which has a t-statistic value of 1,705 is considered 'insignificant' due to it being lower than 1,96. This result does not go accordingly with expert opinion. According to experts, policy has a significant role in BIM data processing, especially in focusing the levels used in BIM since the maintenance object is a high-rise building. Moreover, according to [25], organizations need to develop policies that support the use of BIM, where in the process of design, documentation, structure and facilities visualization, and asset condition report, there needs to be an integration between policies, standards, regulations, and guidelines so that the BIM can run optimally. 


\section{V.I.III Relationship between Policy and Maintenance Performance}

The SEM-PLS analysis results show that the relationship between policy and maintenance performance which has a tstatistic value of 1,314 is considered 'insignificant' due to it being lower than 1,96. This result does not go accordingly with expert opinion. According to experts, the role that policy has on maintenance performance should be highly significant, especially regarding that policy regulations are the fundamental basis of O\&M (operation \& maintenance) in high-rise buildings. This is in accordance to [27] which states that the development of maintenance programs need to be based on policies so that the organization can improve maintenance performance according to standards and regulations.

\section{V.I.IV Relationship between WBS and Maintenance Performance}

The SEM-PLS analysis results show that the relationship between WBS and maintenance performance which has a tstatistic value of 1,217 is considered 'insignificant' due to it being lower than 1,96. This result does not go accordingly with expert opinion. According to the experts, WBS is highly impactful on maintenance performance, especially regarding high-rise building O\&M execution targets. This is in accordance with [28][29] which states that the improvement of maintenance performance must be done with basis on WBS since WBS is capable in facilitating practitioners with information on specific materials and works for each component.

\section{V.I.V Relationship between Guidelines and IS}

The SEM-PLS analysis results show that the relationship between WBS and maintenance performance which has a tstatistic value of 1,141 is considered 'insignificant' due to it being lower than 1,96. According to experts on the field, guidelines have an important role in the information system of the building management's internal organization because a guideline is needed for maintenance officers to be able to use the technologies on the information system. This statement is supported by O'Brien and Marakas in [23], in which is stated that that guidelines are necessary in the process of saving, obtaining, changing, and distributing information in an organization. This is because an information system consists of many elements: human resources, software, hardware, software, and communications network. For this reason, the role of a guideline in an information system of high-rise building maintenance becomes highly important. Moreover, according to [24], the lack of guidelines in the development of information system can cause the documentation system to fail at fulfilling the information requirements of an information system.

\section{V.I.VI Relationship between WBS and BIM.}

The SEM-PLS analysis results show that the relationship between policy and maintenance performance, which has a tstatistic value of 1,079 , is considered 'insignificant' due to it being lower than 1,96 . This result does not go accordingly with expert opinion. According to experts, the WBS have an important, yet indirect, impact on BIM. The experts stated that the WBS is an input in BIM, and vice versa, depending on the level/stage used in the BIM model. This is in accordance to [32] [33] which states that WBS is used as one of the information in the database for the 3D modelling of structural information on BIM. The WBS and WBS codes have an automated connection between tasks and activities in the execution of high-rise building maintenance.

\section{V.I.VI Relationship between Policy and Guidelines}

The SEM-PLS analysis results show that the relationship between WBS and maintenance performance which has a tstatistic value of 0,925 is considered 'insignificant' due to it being lower than 1,96. According to experts, this relationship depends on the scope of the policy itself. If the policy is a policy regulation, then the impact of the policy on high-rise maintenance guidelines is very significant. Moreover, according to [22], policies are capable in being a basis for the formulation of guidelines for the implementation of maintenance strategies which have been effectively chosen.

The existence of a discrepancy between the perspectives of experts and practitioners can be caused by several reasons, one of them being that currently, practitioners often neglect critical components of a maintenance system, especially in the implementation of the latest technologies in maintenance system. This is because practitioners view changes on maintenance performance for the sake of improvement as costly, and thus only comply to reactive and corrective maintenance. However, incremental damage on buildings can become severe if not anticipated, thus making it necessary to conduct proactive and preventive maintenance, in order to avoid material loss and fatalities.

\section{V.II Recommendations}

In this research, a further discussion with experts have been conducted with aims to provide several recommendations based on the inter-variable relationships of e-maintenance of high-rise buildings. The recommendations that are the result of the discussion are as follows.

- Organizations should define a building asset condition index standard that is to be achieved in the execution of building maintenance.

- Organizations should prepare a strategy and develop a strategic plan for short-term and long-term building maintenance activities.

- Organizations should allocate an adequate budget for building maintenance works.

- Organizations should plan and conduct supervision and performance evaluation on building maintenance works.

- Organizations should have a policy for the standardization of WBS. 
- Organizations should have a policy that covers and controls the development and renewal of techniques and use of ICT in high-rise building maintenance with focus on time and cost.

- Organizations should create a clear information flow that is based on RAM/RACI and other technologies in order to create a good relationship among workers and organization leaders that works correctly and efficiently.

- The management of the organization should be supported with a data of available and operational tools and equipment that is accurate and able to notify the management when certain tools are underperforming in order for them to know which maintenance works should be done and therefore achieve better KPI.

- Organizations should group certain information for the public and certain others for the internal of the organization, as well as provide complaint resolution.

- Organizations should prepare an information system that is capable in showing plans, designs, and maintenance works.

- Organizations should formulate a guideline that can be used as a data collection tool and as a scoring indicator for maintenance performance evaluation.

- Organizations should formulate a guideline for WBS-based maintenance where the order of activities for each work package, as well as the resources needed, are clearly stated.

- Organizations should prepare a scheme or roadmap for the implementation of BIM in maintenance work that also contains the methods of the implementation.

- Organizations should facilitate employees with a series of training programs on BIM (starting from the stage of BIM adoption to the stage of wholly and correctly implementing BIM).

- Organizations should facilitate building maintenance with adequate technology so that the implementation of BIM can automize the collection and processing of information on building maintenance quickly and accurately so that a better effectivity and efficiency can be achieved.

\section{CONCLUSION}

Based on the results of SEM-PLS analysis, there are eight intervariable relationships in e-maintenance of high-rise buildings that are considered significant; these eight have t-statistic values of over 1.96. The 8 relationships are policy to WBS, policy to IS, guidelines to maintenance performance, IS to BI, WBS to guidelines, guidelines to BIM, BIM to maintenance performance, and WBS to IS. However, after having a discussion with experts, the experts stated that the intervariable relationships of high-rise building maintenance are all considerably significant. From both these results, it can be concluded that all inter-variable relationships are significant, taking into notice that there exist several perception gaps between practitioners, experts, and literature.
Based on the results of SEM-PLS analysis, an $r$-square value for maintenance performance of 0,794 is obtained. This value shows that the maintenance performance variable is $79,4 \%$ affected by policy, WBS, guidelines, information system, and BIM.

\section{ACKNOWLEDGMENTS}

The Authors would like to thank the financial support provided by Ministry of Research and Technology/National Research and Innovation Agency through PDUPT Grant 2020 with contract number : NKB-2850/UN2.RST/HKP.05.00/2020 managed by the Directorate for Research and Community Engagement(DRPM) Ministry of Research and Technology/National Research and Innovation Agency.

\section{REFERENCES}

[1] Ibrahim E. High Rise Building - Needs \& Impacts. CIB World Building Congress. 2007;1998-2008.

[2] Farouk A. High Rise Buildings and How They Affect Countries Progression. E iataorC Leader.2011.

[3] Ahn D, Cha H. Integration of Building Maintenance Data in Application of Building Information Modeling (BIM). Journal of Building Construction and Planning Research. 2014;166-172.

[4] Mydin M O. Significance of Building Maintenance Management on Life-Span of Buildings. Robotica \& Management. 2017;40-44.

[5] Ismail Z A, Kasim N. Improving Maintenance Management Practices on Conventional Method at Malaysian Polytechnic. Proceedings International Conference of Technology Management, Business and Entrepreneurship. 2012.

[6] Li Y, Chu L, Ching A N. An agent-based platform for Web-enabled equipment predictive maintenance. IEEE/WIC/ACM International Conference on Intelligent Agent Technology. 2005;132-135.

[7] Aziz N, Nawawi A, Ariff N R. Building Information Modelling (BIM) in Facilities Management: Opportunities to be considered by Facility Managers. AMER International Conference on Quality of Life. 2016;353-362.

[8] Wies R. Policy Definition and Classification: Aspects, Criteria, and Examples. International Workshop on Distributed Systems: Operations \& Management. 1996.

[9] Ding S H, Kamaruddin S. Maintenance Policy Optimization-literature review and directions. Int $\mathrm{J}$ Adv Manuf Technol 76. 2015;1263-1283.

[10] PMI. A Guide to the Project Management Body of Knowledge 6th Edition. 2017.

[11] AlFadha A. Can Multidimensional WBS be the Solution for IT Project Issues?. PM World Journal. 2014;1-12. 
[12] Laudon K C, Laudon J P. Management Information Systems, 13th Edition. Harlow: Pearson. 2014.

[13] Lipaj D, Davidavičienè V. Influence of Information Systems on Business Performance. Business in XXI century. 2013;38-45.

[14] Medakovic V, Maric B. A Model of Management Information System for Technical System Maintenance. ACTA TECHNICA CORVINIENSIS. 2018;85-90.

[15] Politi R R, Aktaş E, İlal M E. Project Planning and Management Using Building Information Modeling (BIM). 13th International Congress on Advances in Civil Engineering. 2018;1-8.

[16] Li J, et al. Benefits of Building Information Modelling in the Project Lifecycle: Construction Projects in Asia. International Journal of Advanced Robotic Systems. 2014;1-11.

[17] Motawa I, Almarshad A. A Knowledge-based BIM System for Building Maintenance. Automation in Construction. 2013;173-182.

[18] Weber A, Thomas R. Key Performance Indicators: Measuring and Managing the Maintenance Function. Canada: IVARA CORPORATION. 2005.

[19] Samat H A, Kamaruddin S, Azid I A. Maintenance Performance Measurement: A Review. Pertanika J. Sci. \& Technol. 2011;199-211.

[20] Lavold G. Developing and Using The Work Breakdown Structure. Project Management Handbook, Second Edition. Ed. David I. Cleland and William R. King. New York: Wiley. 1997;302-323.

[21] The Audit Office of Guyana. Rules, Policies, and Procedures Manual. The Audit Office of Guyana. 2004.

[22] Velmurugan R S, Dhingra T. Maintenance Strategy Selection and Its Impact in Maintenance Function. International Journal of Operations \& Production Management. 2015;1622-1661.

[23] Al-Mamary Y H, Shamsuddin A, Aziati N. The Role of Different Types of Information Systems In Business Organizations : A Review. International Journal of Research. 2014;1279-1286.

[24] Oprea D, Mesnita G. The Information Systems Documentation - Another Problem for Project Management. Managing Information in the Digital Economy. 2006;332-338.

[25] Wang G, Song J. The Relation of Perceived Benefits and Organizational Supports to User Satisfaction with Building Information Model (BIM). Computers in Human Behavior. 2017;493-500.

[26] Post N. Building Team Members See Progress and Problems. Eng. News-Rec. 2009.
[27] Parida A, Kumar U. Maintenance Performance Measurement (MPM): Issues and Challenges. Journal of Quality in Maintenance Engineering. 2006;239-251.

[28] Ilham R M, et al. Development of MaintenanceReparation Guidance, and Material Specification for Green Building's Electrical Component in Government Building Based on Work Breakdown Structure (WBS). 3rd International Conference on Energy Materials and Applications. IOP Publishing. 2018.

[29] Djonli Y, Latief Y, Machfudiyanto R A. Preventive maintenance of mechanical component development guideline on government building based work breakdown structure. Journal of Physics: Conference Series 1516. 2020

[30] Brandon D. Project Management for Modern Information Systems. London: IRM Press. 2006.

[31] Ibrahim Y M, et al. Semi-Automatic Development of The Work Breakdown Structure (WBS) for Construction Projects. 4th International SCRI Research Symposium. 2007;133-145.

[32] Lee D G, et al. BIM-Based Construction Information Management Framework for Site Information Management. Advances in Civil Engineering. 2018;114.

[33] Ratajezak J, et al. BIM-Based Augmented Reality Tool for The Monitoring of Construction Performance and Progress. European Conference on Computing in Construction. 2019;467-490.

[34] Olawumi T O, Chan D W M. Building Information Modelling and Project Information Management Framework for Construction Projects. Journal of Civil Engineering and Management. 2019; 53-75.

[35] Azhar S. Building Information Modeling (BIM): Trends, Benefits, Risks, and Challenges for the AEC Industry. Leadership and Management in Engineering. 2011;241-252.

[36] Vaisnys P, et al. Benchmarking Study of Maintenance Performance Monitoring Practices Summary Report. Petten: European Commision. 2007.

[37] Heaton J, et al. Design and Development of BIM Models to Support Operations and Maintenance. Computers in Industry. 2019;172-186.

[38] Haenlein M, Kaplan A M. A Beginner's Guide to Partial Least Squares Analysis. Understanding Statistics. 2004;283-297.

[39] Wong K. Partial Least Squares Structural Equation Modeling (PLS-SEM) Techniques Using SmartPLS. Marketing Bulletin. 2013;1-32. 